\title{
VDT microplane model with anisotropic effectiveness and plasticity
}

\author{
Abdelkibir BENELFELLAH ${ }^{\mathrm{a}}$, Michel GRATTON ${ }^{\mathrm{b}}$, Michael CALIEZ ${ }^{\mathrm{b}}$, \\ Arnaud FRACHON ${ }^{b}$, Didier PICART ${ }^{c}$ \\ a. Institut Pprime (UPR CNRS 3346) - ENSMA/Université de Poitiers/CNRS \\ 1, avenue Clément Ader - BP 40109 - 86961 Futuroscope Cedex, benelfellah@ensma.fr, \\ b. Laboratoire de Mécanique et Rhéologie, E.A. 2640, B.P. 3410, INSA-CVL, Université François \\ Rabelais de Tours, 41034 Blois CEDEX, France, \\ michel.gratton@insa-cvl.fr, michael.caliez@insa-cvl.fr, arnaud.frachon@insa-cvl.fr \\ c. CEA, DAM, Le Ripault, F-37260 Monts France, didier.picart@cea.fr
}

\section{Résumé :}

L'état de l'ouverture et de la fermeture des microfissures est un phénomène cinématique généralement modélisé à l'aide de variables d'effectivité de l'endommagement, qui conduit à une élasticité différente pour un même niveau de dommage. Dans ce travail, le modèle microplan avec une décomposition Volumétrique, Déviatorique et Tangentiel (VDT), est sélectionné et modifié en introduisant l'effet d'ouverture-fermeture des microfissures dans l'énergie libre. Une loi d'évolution de l'endommagement est écrite pour mieux prendre en compte l'influence de la pression sur l'endommagement. Afin de mieux illustrer les mécanismes introduits dans le modèle, des rosettes de dommage pour un niveau de déformation donné sont présentées. Le modèle est validé en comparant les simulations aux résultats expérimentaux pour des essais monotones et cycliques de traction et compression avec différents niveaux de confinement.

\section{Abstract:}

The opening-closing state of the microcracks is a kinematic phenomenon usually modeled using a set of damage effectiveness variables, which results in different elastic responses for the same damage level. In this work, the microplane model with volumetric, deviatoric and tangential decomposition denoted V-D-T is modified. The influence of the confining pressure is taken into account in the damage variables evolution laws. For a better understanding of the mechanisms introduced into the model, the damage rosettes are presented for a strain given level. The model is confirmed through comparisons of the simulations with the experimental results of monotonic, and cyclic tensile and compressive testing with different levels of confining pressure.

Key words: induced anisotropy, damage effect, microcracks, constitutive modeling, microplane, plasticity. 


\section{$1 \quad$ Introduction}

Quasi-brittle materials are characterized by an asymmetric behavior in tension and compression, and a dependence of the damage evolution to the confining pressure (influence of microcracks closure). This damage effectiveness has been sometimes modeled by using two different damage variables to separate the opening and closing states [12]. Others authors had introduced a set of variables or dependent parameters, often inspired by the mechanisms at the microstructure level such as the blocked energy by closed defects [7] [14], or a $4^{\text {th }}$ order tensor parameter (Halm and Dragon 2002), but also open microcracks ratio (Baste et al. 1989), and the opening mode cracks concept [17] [18], etc. We choose here a microplane formalism introduced in 1938 (Taylor [16]) and first applied to metal plasticity (Batdorf Budianski [1]). Since, they have been applied to brittle materials (concrete, ceramics, rocks, ice, ...). For example, we can cite the work of Bazant et al. [2] [3] [4] [5] [8] Carol et al. [9] [11] and Ramm et al. [10] [13]. A detailed comparison of the main classes of those models is presented by Benelfellah et al. [6].

Microplane models consider that each direction of the solid angle chosen fixed, orients a microplane with its associated behavior. The global deformations are projected on each microplane. There are several types of formulations and we will focus on the VDT one (Volumetric, Deviatoric and Tangential). A constitutive law in the plane defines the state of stress associated from the projected deformations. The global stress is built respecting the principle of virtual work, from the stress on each microplane, through an integral over the whole solid angle. In the following simulations, the solid angle is discretized into 42 equally spaced angular sectors, ensuring the ability to describe the elastic isotropy.

\section{VDT model with effectiveness of damage}

Bazant and Gambarova [2] presented this approach to simulate the response of concrete submitted to compressive loading. This formulation is based on the decomposition of the strain tensor for a given direction $\mathbf{n}$ in a tangential part $\overrightarrow{\boldsymbol{\varepsilon}}_{T}$, and a normal one which is composed of a volumetric part, $\varepsilon_{V}$, and a deviatoric one $\varepsilon_{D}$ (figure 1).
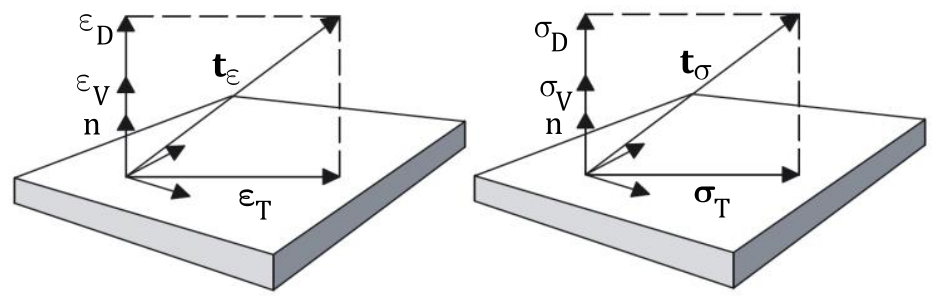

Figure 1 : VDT decomposition [11]

$$
\begin{array}{ll}
\varepsilon_{V}=\mathbf{V}: \varepsilon, \quad \varepsilon_{D}=\mathbf{D}: \varepsilon, \quad \vec{\varepsilon}_{\boldsymbol{T}}=\mathbf{T}: \boldsymbol{\varepsilon} \\
\mathbf{V}=\frac{1}{3} \mathbf{1} \quad, \quad \mathbf{D}=\mathbf{n} \otimes \mathbf{n}-\frac{1}{3} \mathbf{1} \quad, \quad \mathbf{T}=\mathbf{n} . \mathbb{I}-\mathbf{n} \otimes \mathbf{n} \otimes \mathbf{n}
\end{array}
$$

The consequences of opening / closing of microcracks on the effect of damage are introduced into the free energy of each microplane using effectiveness functions denoted $\alpha_{V}\left(\varepsilon_{V}\right), \alpha_{D}\left(\varepsilon_{D}\right)$ and $\alpha_{T}\left(\varepsilon_{T}\right)$ [6].

The free energy for a given microplane is thus expressed:

$$
\begin{aligned}
\Psi^{m i c} & =\frac{1}{2} k_{V}\left(1-\alpha_{V}\left(\varepsilon_{V}\right) d_{V}\right) \varepsilon_{V}^{2}+\frac{1}{2} \mu_{D}\left[\left(1-\alpha_{D}\left(\varepsilon_{D}\right) d_{D}\right) \varepsilon_{D}^{2}\right] \\
& +\frac{1}{2} \mu_{T}\left[\left(1-\alpha_{T}\left(\varepsilon_{T}\right) d_{T}\right) \varepsilon_{T} \cdot \varepsilon_{T}\right]
\end{aligned}
$$

Applied to microplane, the second principle leads to the equation (4) and must be verified for any loading path. It results a first part giving the state variables laws at the microplane level and a second 
part giving the dissipation due to damage growth whose the positivity is usually guaranteed by the damage irreversibility. Three dissipative terms, dependent on the effectiveness evolution, appear (second line of equation (4)), and raise two questions. Should these terms be zero? If they are not null, what their physical senses? One approach is to assume non-dissipative effectiveness mechanisms (no hysteresis phenomena for example), and these terms should then always remain zero. A second approach is to introduce a dissipation, due to the effectiveness, whose the positivity and the physical interpretation must be given.

$$
\begin{aligned}
\mathcal{D}^{m i c} & =\left[\sigma_{V}-\frac{\partial \Psi^{m i c}}{\partial \varepsilon_{V}}\right] \dot{\varepsilon}_{V}+\left[\sigma_{D}-\frac{\partial \Psi^{m i c}}{\partial \varepsilon_{D}}\right] \dot{\varepsilon}_{D}+\left[\sigma_{T}-\frac{\partial \Psi^{m i c}}{\partial \varepsilon_{T}}\right] \cdot \dot{\varepsilon}_{T} \\
& -\frac{\partial \Psi^{m i c}}{\partial \alpha_{V}} \dot{\alpha}_{V}\left(\varepsilon_{V}\right)-\frac{\partial \Psi^{m i c}}{\partial \alpha_{D}} \dot{\alpha}_{D}\left(\varepsilon_{D}\right)-\frac{\partial \Psi^{m i c}}{\partial \alpha_{T}} \dot{\alpha}_{T}\left(\varepsilon_{T}\right) \\
& -\frac{\partial \Psi^{m i c}}{\partial d_{V}} \dot{d}_{V}-\frac{\partial \Psi^{m i c}}{\partial d_{D}} \dot{d}_{D}-\frac{\partial \Psi^{m i c}}{\partial d_{T}} \dot{d}_{T} \geq 0
\end{aligned}
$$

For simplicity's sake, the function of volumetric effectiveness $\alpha_{V}\left(\varepsilon_{V}\right)$ is a Heaviside function of the observable variable $\varepsilon_{V}$ which guarantees the nullity of the term $\frac{\partial \Psi^{m i c}}{\partial \alpha_{V}} \dot{\alpha}_{V}\left(\varepsilon_{V}\right)$. This function may easily be replaced by a continuously differentiable function, changing therefore the elasticity law. We accept a partial effectiveness of $50 \%$ on the deviatoric damage when microcracks are "closed" $\left(\varepsilon_{D} \leq 0\right)$. The tangential damage is considered always effective $\left(\alpha_{T}\left(\boldsymbol{\varepsilon}_{T}\right)=1\right)$. Thus:

$$
\begin{aligned}
&\left\{\begin{aligned}
\varepsilon_{D} & \leq 0 \Rightarrow \alpha\left(\varepsilon_{D}\right)=0,5 \\
\varepsilon_{D} & >0 \Rightarrow \alpha\left(\varepsilon_{D}\right)=1
\end{aligned}\right. \\
& \boldsymbol{\sigma}=\frac{3}{4 \pi} \rho_{0} \int_{\Omega}\left[k_{V}\left(1-\alpha_{V}\left(\varepsilon_{V}\right) d_{V}\right) \varepsilon_{V}\right] \mathbf{V} \\
&+\left[\mu_{D}\left(1-\alpha_{D}\left(\varepsilon_{D}\right) d_{D}\right) \varepsilon_{D}\right] \mathbf{D}+\left[\mu_{T}\left(1-d_{T}\right) \boldsymbol{\varepsilon}_{T}\right] \cdot \mathbf{T} d \Omega
\end{aligned}
$$

\section{Identification and damage evolution law}

Tests called "H10" (respectively "H05") consist in two main steps; a hydrostatic confinement one until $10 \mathrm{MPa}$ (respectively $5 \mathrm{MPa}$ ) followed by a cyclic longitudinal compression one. Tests called "TS" referred to simple tensile test and "CS" to the simple compressive test.

It is difficult to identify microplane models because the experimental overall response results from the sum of the elementary responses on each plane, and thus is different from the "local" response of the microplane. It is therefore necessary to apply at first basic behaviors on microplane to identify afterwards the consequences once the global stress tensor is obtained.

Damage variables are expected to evolve according to the associated thermodynamic forces $F^{d_{i}}$, calculated from the free energy. Like the model proposed by Bazant et al., A dependency of the damage evolution at the volume change using the $p$ parameter is added. The evolution laws are given by the following relationships:

$$
\begin{aligned}
& d_{i}\left(F^{d_{i}}, p\right)=\max _{t}\left(d_{i}^{0}, 1-\exp \left(-p\left[a_{3} F^{d_{i}}\right]^{a_{4}}\right)\right) \text { with } 0 \leq d_{i} \leq 1 \\
& p=1+a_{5} k_{V}^{0}<\varepsilon_{V}-\varepsilon_{V 0}^{H 10}>_{+}
\end{aligned}
$$

Where $d_{i}^{0}$ is the initial damage of the material ( $i$ replaces indices V, D or T). $a_{3}, a_{4}$ and $a_{5}$ are parameters to identify. $\varepsilon_{V 0}^{H 10}$ is the negative volumetric strain attained after the isostatic confinement of $10 \mathrm{MPa}$. Thus, the variable $p$ is equal to 1 at the start of the compression phase of the test H10 $\left(\varepsilon_{V}=\varepsilon_{V 0}^{H 10}\right)$ and it is higher than 1 at the beginning of the compressive test CS without confinement. Figure 2 illustrates the effect of the parameters on the damage evolution. 


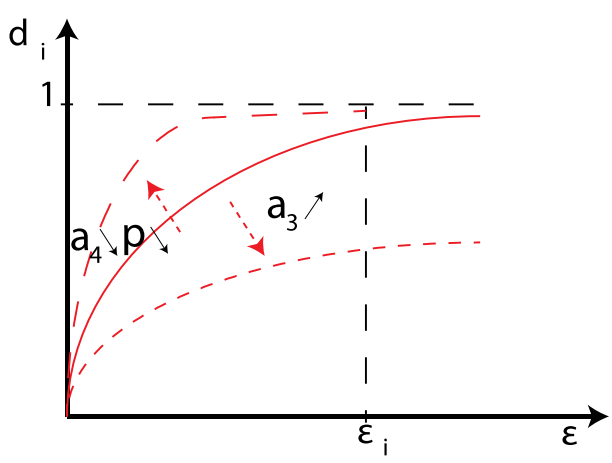

Figure 2 Effect of the damage parameters on the damage variable evolution

Dependence on the pressure of the response of the material and its initial microcracking led to consider this material pre-damaged.

\begin{tabular}{cccccccc}
\hline $\begin{array}{c}k_{V}^{0} \\
(\mathrm{MPa})\end{array}$ & $\begin{array}{c}\mu_{D}^{0}=\mu_{T}^{0} \\
(\mathrm{MPa})\end{array}$ & $d_{V}^{0}$ & $d_{D}^{0}=d_{T}^{0}$ & $a_{3}$ & $a_{4}$ & $a_{5} / a^{\prime}{ }_{5}$ & $\varepsilon_{V}^{0}$ \\
\hline 21500 & 3070 & 0.2 & 0.1 & 12 & $2 / 3$ & $0.25 / 1.5$ & $4.65 \mathrm{e}-4$ \\
\hline
\end{tabular}

Table 1 : Model parameters identified for an energetic material

\section{Simulation and comparison to experimental results}

To introduce residual strain, a parabolic isotropic yield criteria in the plane (effective pressure $\widetilde{\sigma}_{V}-$ effective octahedral stress $\widetilde{Q}$ ) is "added" to the microplane model. The determination of the yield surface and the flow law, and the identification of the strain hardening are carried out from Le [19].

$$
\sigma^{V}=\frac{1}{3} \operatorname{tr}(\boldsymbol{\sigma}), Q=\sqrt{\frac{1}{3} \boldsymbol{\sigma}^{d e v}: \boldsymbol{\sigma}^{d e v}} \text { with } \boldsymbol{\sigma}^{d e v}=\boldsymbol{\sigma}-\frac{1}{3} \operatorname{tr}(\boldsymbol{\sigma})
$$

The effective stress is determined using the $4^{\text {th }}$ order damage operator $(\boldsymbol{I}-\boldsymbol{D})^{-1}$ calculated by the microplane part of the model: $\widetilde{\boldsymbol{\sigma}}=(\boldsymbol{I}-\boldsymbol{D})^{-1}: \boldsymbol{\sigma}$.

The simulations of tensile test, compressive test and compressive test with confining pressure at 5 and $10 \mathrm{MPa}$ for the complete model are compared with the experimental responses in Figure 3. The simulations are interrupted just after the last experimental point. The experimental responses in tensile test and compression test are quite well reproduced. Zooming in on figure 3 could show a slight difference in the tension and compression moduli. In a confined compressive test, a higher modulus at the origin is found and the damage evolve more slowly because of the confining pressure term in the evolution law. Figure 4 compares the simulation to the response of a confined multi cyclic test (10 $\mathrm{MPa}$ ). The reported points along the axes for a stress of $-10 \mathrm{MPa}$ correspond to residual strain. In this figure the residual strains of the model are similar to the experimental ones. The balance between damage and plasticity observed during discharges is quite good. 


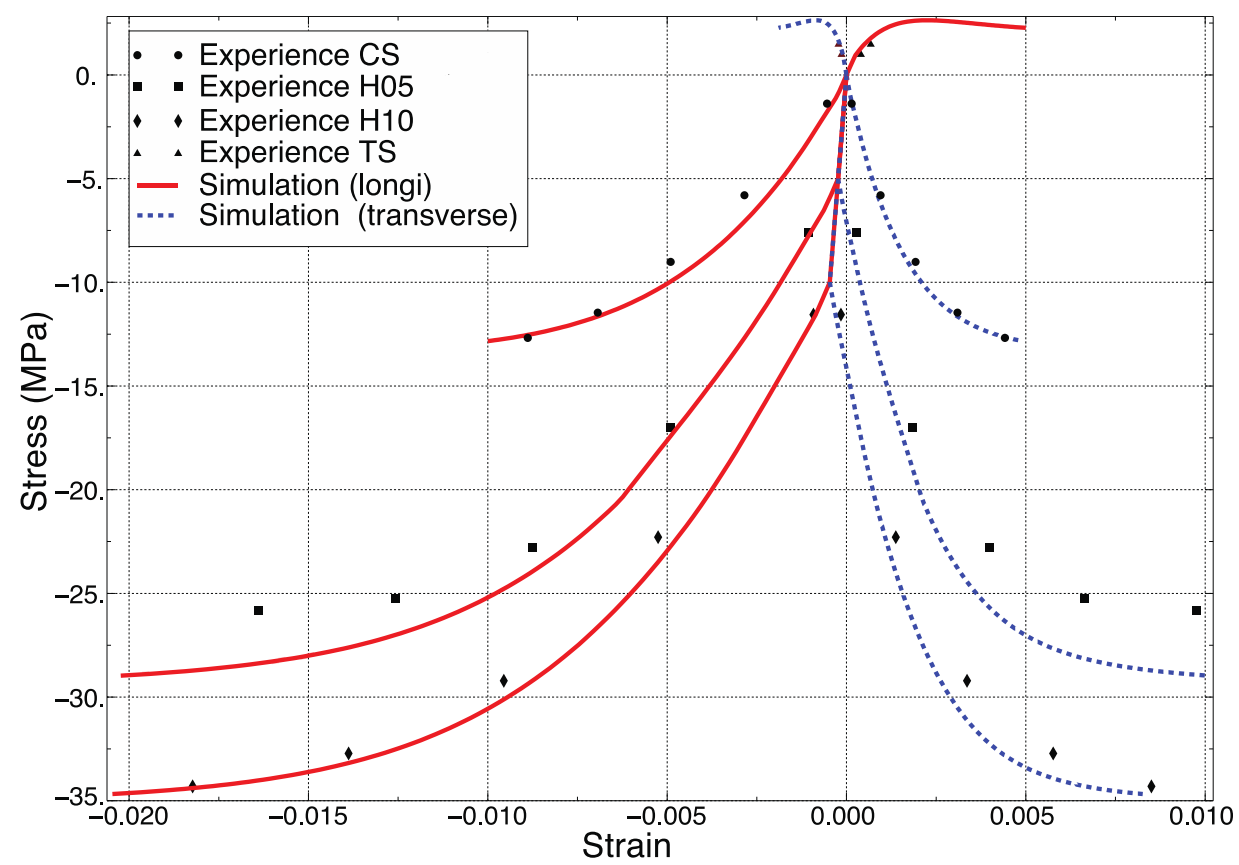

Figure 3 : Simulation of tensile test, compression test and compression with confining pressure (5 to $10 \mathrm{MPa}$ ) for an aggregate energetic material.

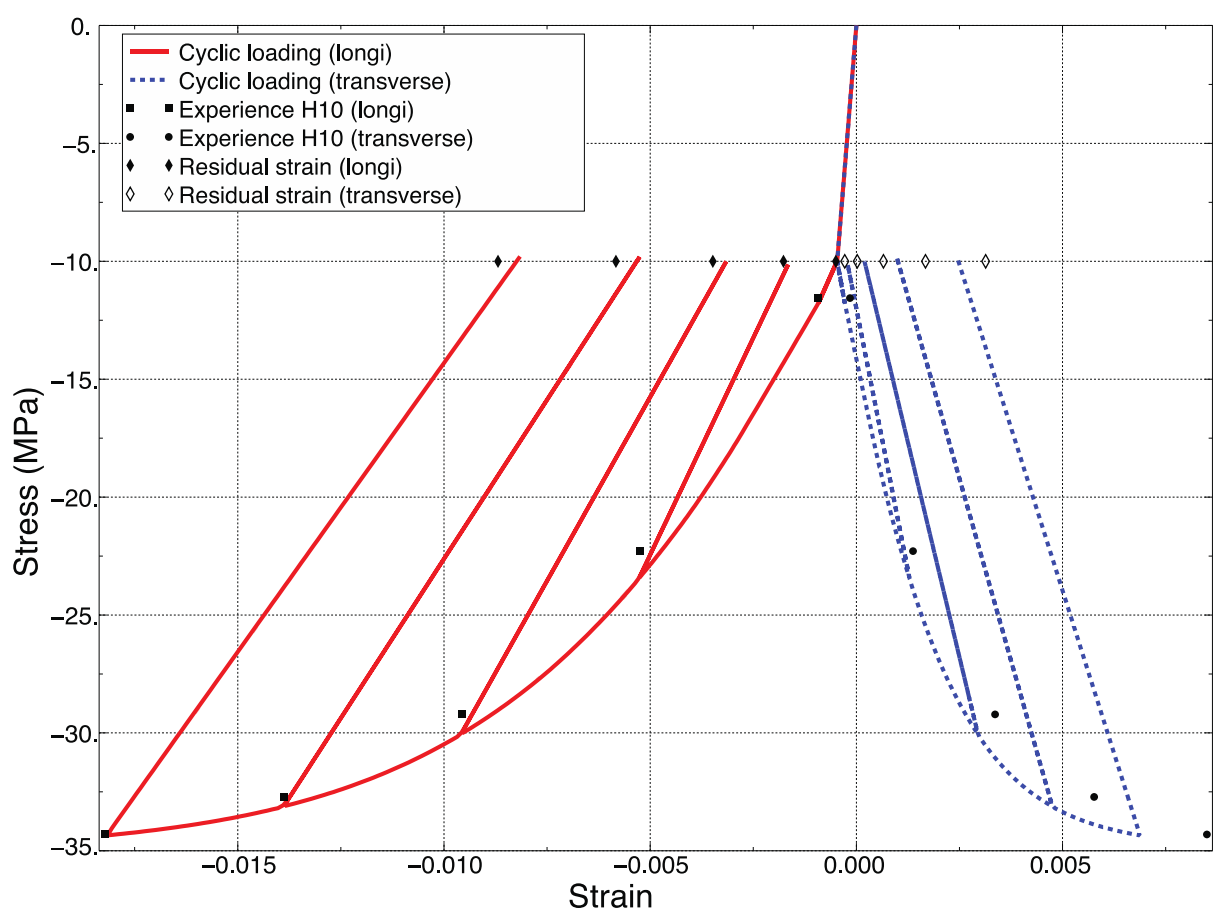

Figure 4 : Simulation of cyclic compression with confinement (10 MPa) for an aggregate energetic material

Given the lack of experimental data for non-proportional multiaxial loading, the influence of the effectiveness and the damage anisotropy can be analyzed only by the model. The damage distribution is presented for a given value of the longitudinal strain $(1 \%)$ in a plane containing the loading direction $\boldsymbol{e}_{\mathbf{1}}$ (Figure 5A, B). Firstly, there is a strong anisotropy of the tangential damage ("ם"), which is maximum in the longitudinal and transverse directions, and the deviatoric damage ('+'), which is maximum in a $45^{\circ}$ direction relative to the loading one $\boldsymbol{e}_{\mathbf{1}}$. Note that in the loading direction, the effective deviatoric damage ('o') is half that calculated (' + ') because of the effectiveness parameter. For 
the same level of $1 \%$ strain, we note that the damage for compressive test with confining pressure is less developed than in compressive test without pressure, finding thus the limiting effect of the confining pressure on the damage evolution.
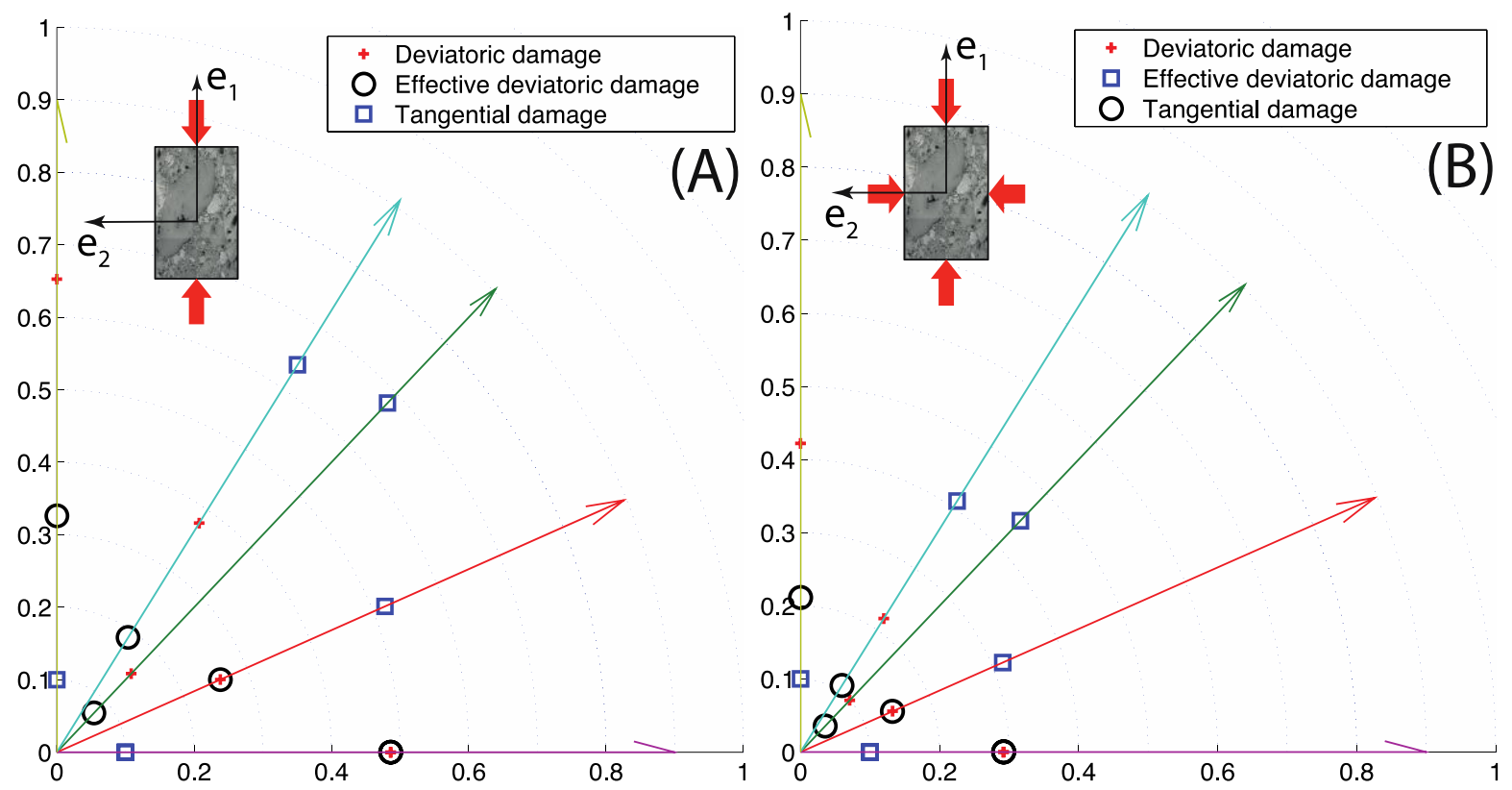

Figure 5 : Rosette of damage for $1 \%$ of longitudinal strain in compressive test (A) and triaxial compressive test with $10 \mathrm{MPa}$ of confinement (B). $\boldsymbol{e}_{\mathbf{1}}$ is the loading direction.

\section{Conclusion}

In this article two phenomena of effectiveness have been introduced into the VDT model respecting the thermodynamic framework. To ensure zero dissipation, these mechanisms are governed by the associated deformations. Simple Heaviside functions have been used to manage the stiffness changes on each microplane. With regard to deviatoric damage, the loss or the recovery of the modulus is partial when changing from tension to compression. No dissipative mechanism being introduced, the stiffness discontinuities occur for a null elastic strain to cancel the strain jump that could results from the variation of stiffness. For compression loads, pressure effect has been take into account in the evolution of the damage. This allows to identify the model from the triaxial test "H10" and then translate the behavior observed for compressive test. As commonly seen in some concrete models, we have integrated two damage laws to control tension-compression asymmetry.

The plastic behavior has been "added" to the damageable elastic model to predict permanent deformations experimentally observed. Anisotropic effective stress formalism has permitted a decoupling of plasticity and damage. The treatment of results has been adapted and the parameters redetermined. Comparisons between calculations and experiments show a quite good agreement even if a final optimization of the parameters is necessary to further increase thereof. 


\section{Références}

[1] S. Batdorf, B. Budiansky. A mathematical theory of plasticity based on the concept of slip, volume Technical Note No. 1871. National Advisory Committee for Aeronautics, 1949.

[2] Z. P. Bazant, P. G. Gambarova. Crack shear in concrete: Crack band microplane model. Journal of Structural Engineering, 110(9) 2015-2035, 1984.

[3] Z. P. Bazant, B. H. Oh, Deformation of cracked net-reinforced concrete walls. Journal of Structural Engineering, 109(1) 93-108, 1983.

[4] Z. P. Bazant, B. H. Oh. Microplane model for progressive fracture of concrete and rock. Journal of Engineering Mechanics, 111(4) 559-582, 1985.

[5] A. Beghini, Z. P. Bazant, Y. Zhou, O. Gouirand, F. C. Caner. Microplane model m5f for multiaxial behavior and fracture of fiber-reinforced concrete. Journal of Engineering Mechanics, 133(1) 66-75, 2007.

[6] A. Benelfellah, A. Frachon, M. Gratton, M. Caliez, D. Picart, Analytical and numerical comparison of discrete damage models with induced anisotropy. Engineering Fracture Mechanics 21122 (2014) 28-39

[7] A. Boursin, J. L. Chaboche, F. Roudolf. Mécanique de l'endommagement avec conditions unilatérales et stockage d'énergie élastique. Comptes Rendus de l'Académie des Sciences Paris, Série II(323) :369-376, 1996.

[8] I. Carol, M. Jiràsek, Z. Bazant. A thermodynamically consistent approach to microplane theory. part I. free energy and consistent microplane stresses.International Journal of Solids and Structures, 38(17) 2921-2931, 2001.

[9] I. Carol, K. Willam. Spurious energy dissipation/generation in stiffness recovery models for elastic degradation and damage. International Journal of Solids and Structures, 33(20-22) (1996) 2939-2957.

[10] E. Kuhl, E. Ramm, R. Borst, An anisotropic gradient damage model for quasi-brittle materials. Computer Methods in Applied Mechanics and Engineering, 183(1-2) (2000) 87 - 103.

[11] E. Kuhl, P. Steinmann, I. Carol. A thermodynamically consistent approach to microplane theory. part II. dissipation and inelastic constitutive modeling. International Journal of Solids and Structures, 38(17) 2933-2952, 2001.

[12] P. Ladeveze, A. Gasser, O. Allix. Damage mechanisms modeling for ceramic composites. Journal of Engineering Materials and Technology, 116(3) 331-336, 1994.

[13] M. Leukart, E. Ramm, A comparison of damage models formulated on different material scales. Compt Mat Sce, 28(3-4):749-762. Twelfth Int Workshop on Compt Mech of Mat., 2003.

[14] J.F. Maire, J.L. Chaboche. A new formulation of continuum damage mechanics (CDM) for composite materials. Aerospace Science and Technology, 1(4) 247- 257, 1997.

[15] D. Picart, A. Benelfellah, J. L. Brigolle, A. Frachon, M. Gratton, M. Caliez, Characterization and modeling of the anisotropic damage of a high explosive composition. Engineering Fracture Mechanics 131 (2014) 525-537

[16] G. I. Taylor, Plastic strain in metals. Journal Institute of Metals, 62 307-324, 1938.

[17] A. Thionnet. From fracture to damage mechanics: A behavior law for microcracked composites using the concept of crack opening mode. Composite Structures, 92(3) 780-794, 2010.

[18] A. Thionnet, J. Renard. Modelling unilateral damage effect in strongly anisotropic materials by the introduction of the loading mode in damage mechanics. International Journal of Solids and Structures, 36(28) 4269- 4287, 1999.

[19] V. D. Le, Modélisation et identification du comportement plastique visco-élastique endommageable d'un matériau agrégataire. Thèse, Université François Rabelais de Tours, 2007. 